\title{
MAPPING COASTAL ICE CLIFFS AND ICEBERGS FROM ALTIMETRY DATA
}

\section{(Abstract)}

by

\author{
R.H. Thomas
}

(Space Department, R.A.E., Farnborough, Hampshire GU14 6TD, UK)

and H. Jay Zwally

(NASA, Goddard Space Flight Center, Laboratory for Oceans, Greenbelt, MD, U.S.A.)

\begin{abstract}
In a recent paper, Thomas et.al. (1984) showed how the coast of Antarctica could be mapped using satellite altimetry data. As the satellite approached the continent from the ocean, the Seasat altimeter obtained strong reflections from sea ice, even for a short time after passing over the ice front. Measured ranges are actually oblique distances to the nearest portion of sea ice, yielding a false drop in surface elevation. From the sequence of oblique ranges during a single orbit crossing of the ice cliff, the horizontal position of a segment of the ice cliff is mapped. Currently, the entire Seasat data set is being analyzed to map most of the Antarctic coastline north of $72^{\circ} \mathrm{S}$ to an accuracy of \pm 0.1 to $1 \mathrm{~km}$, which is a major improvement over existing surveys. The altimeter waveforms corresponding to each range measurement are computer analyzed ("retracked"), using procedures that account for the specular reflections from sea ice and the diffuse reflections from firn. Each waveform analysis, along with the corrected range for data
\end{abstract}

obtained in the vicinity of an ice cliff crossing, is verified or recomputed on an interactive computer, which also computes and maps the position of the ice front. The locations of several tabular icebergs have also been mapped with the same procedures, which can ultimately be used to obtain an estimate of iceberg population density in polar waters. Initial results include the mapping of the Larsen ice shelf on the eastern side of the Antarctic Peninsula, showing, for example, the protrusion at approximately $68.5^{\circ} \mathrm{S}$. Estimates of errors in the derived horizontal position are obtained from the analysis of data from repeating orbit tracks. Comparison of these results with results from future altimetry missions will reveal changes in the position of coastal ice cliffs, due to ice movement and/or iceberg calving. Systematic measurements over several years would probably distinguish the effects of iceberg calving, which is intermittent, from those of ice movement, which is continuous. 